\title{
An improved desiccant evaporative cooling system, parametric analysis, and system comparison
}

\author{
A.Zaher", E. Elgendy, S. Shabaan \\ Mechatronics Engineering Department, Faculty of Engineering at Arab Academy of Science \\ and Technology, 2033 El-Horya Heliopolis, Cairo, Egypt.
}

\begin{abstract}
This paper discusses a new cooling system that improves the performance of the ventilation cycle for the desiccant evaporative cooling system. The present work is compared with previous studies under various conditions of ambient temperature and humidity ratios. All systems are developed and tested by terms of TRNSYS software through which the validation process is also performed. New components are used with different configurations to enhance the cooling of the supplied air. The results of the validation model show a good agreement with the previously studied cycle with average errors of $1.8 \%$ and $0.74 \%$ for ambient temperature and humidity respectively. The new system recorded higher performance characteristics over the previously studied systems also Exergy efficiency improved by $19.7 \%$.
\end{abstract}

Keywords: Desiccant cooling - Evaporative cooling - Enhancement of desiccant conventional cycle.

* Corresponding author. Tel.: (002) 01096914933.

E-mail address: a_s_zaher@yahoo.com 


\section{Nomenclature}

\section{Symbols}

\begin{tabular}{ll}
\hline$\dot{\mathrm{E}}$ & exergy rate $(\mathrm{kW})$ \\
$\mathrm{h}$ & specific enthalpy $(\mathrm{kJ} / \mathrm{kg})$ \\
$\square$ & mass flow rate $(\mathrm{kg} / \mathrm{s})$ \\
$\mathrm{Q}$ & heat transfer rate $(\mathrm{kW})$ \\
$\mathrm{T}$ & temperature $(\mathrm{K})$ \\
$\mathrm{w}$ & humidity ratio $(-)$
\end{tabular}

\section{Greek Symbols \\ efficiency}

\section{Subscripts}

\begin{tabular}{ll}
\hline a & air \\
amb & ambient \\
$\mathrm{c}$ & Carnot \\
cool & cooling \\
$\mathrm{cs}$ & conditioned space \\
$\mathrm{d}$ & handling \\
$\mathrm{des}$ & destruction \\
$\mathrm{ex}$ & exergy \\
$\mathrm{he}$ & heat engine \\
reg & regeneration \\
$\mathrm{r}$ & refrigerator \\
sor & source \\
th & thermal \\
tot & total
\end{tabular}

\section{Abbreviations}

CFCs chlorofluorocarbons

COP coefficient of performance

CVCR conventional vapor compression refrigeration

DCS desiccant cooling system

DEC direct evaporative cooler

DIEC direct/indirect evaporative cooler

DW desiccant wheel

GHG greenhouse gas

GWP global warming potential

HCFCs hydrochlorofluorocarbons

HFC hydrofluorocarbons

HS heat source

HVAC heating, ventilation and air conditioning

IEC indirect evaporative cooler

ODP ozone layer depletion potential

RHEX rotating heat exchanger

VCS vapor compression system

\section{Introduction}

The world's energy consumption rising rate is being estimated to rise by about $35 \%$ from 2010-2035 [1]. The total energy consumption by the building sector is about 30$40 \%$, of which about $50 \%$ of this is being consumed by the heating, ventilation and air conditioning (HVAC) systems to provide human comfort [2]. Air conditioning (AC) use is predicted to be the second-largest source of global electricity demand growth after the 
industry sector, consequently, global energy demand from air conditioners is expected to triple by 2050 [3].

Air conditioning in recent days among most parts of the world is done by conventional vapor compression refrigeration (CVCR) based air conditioners operated by a large amount of high-grade electrical energy. The heart of the CVCR system lies in the refrigerant, whose chemistry has evolved in response to policy and environmental concerns, from chlorofluorocarbons (CFCs) and HCFCs which are banned under the Montreal Protocol in 1987 [4], to HFCs [5]. CVCR based air conditioners usage has led to increased CFC (Freon) levels \& greenhouse gas (GHG) emissions, resulting in the ozone layer depletion potential (ODP) and global warming potential (GWP) thus environmental concerns can no longer be overlooked. All the above-mentioned issues combined with CVCR systems have compelled researchers to investigate alternative technologies for air conditioning to overcome the above-mentioned issues [6,7].

Desiccant cooling systems (DCSs) are brought into consideration as one of the most promising solutions of air conditioning, which were able to replace an important part of the mechanical- compression systems [8,9,10]. They are Capable of both drying \& filtering air making its performance more suitable for weather conditions such as the Mediterranean region. Moreover, they are considered to be environmentally friendly due to the absence of CFCs, hydrochlorofluorocarbons (HCFCs) or hydrofluorocarbons (HFCs) refrigerants. The DCS maintains required indoor comfort by optimal use of thermal energy with least electrical power, thus reducing negative effects of CVCR systems, because they can be driven by exploiting low-grade thermal energy such as solar energy, waste heat, geothermal, and natural gas [11, 12]

Desiccants are functioning on the vapor pressure difference between the absorbent and the air. There are two major desiccant technologies including solid and liquid desiccants. The main components of Liquid desiccant are an absorber and a regenerator [13]. One of the main disadvantages of liquid desiccants is that the probability of a portion of absorbent to be carried away by the air stream through the absorption and regeneration processes [14].

Solid desiccant air conditioning systems are a riveting alternative to vapor compression systems [15]. Solid desiccant is available in different forms such as stationary or rotary wheels, fixed bed, cross-flow bed and belt [16]. Desiccant wheel has captivated most of the attention, as it occupies less space and works uninterruptedly without any sensitivity to corrosion. Recent studies on rotary desiccants are mainly based on two main goals, the development of advanced desiccant materials and identification of the most efficient system configurations [17]. Daou et al. [18] reviewed different configurations of DCS and La et al. [19] highlighted the main advantages of the solid rotary DCS, which are compactness, operate without any disruption meaning continuous working hours, and lower susceptibility to corrosion during operation making it more appropriate for air conditioning purposes. 
Silica gel, alumina silicate, and zeolite are the most commonly employed materials for solid desiccants [16]. Direct and indirect types are two major kinds of evaporative coolers. Each type has experienced different improvements to achieve better performance through the years [20]. DCSs' initial versions were using the direct evaporative coolers, however, as a result of the low effectiveness of direct process, the indirect evaporative air coolers are believed to be the new essential cooling source in these systems. Furthermore, to using individually, these two types can function together and make a DIEC, which has the major benefits of both direct evaporative cooler (DEC) and indirect evaporative cooler (IEC) simultaneously [21], besides it applies to the very hot and dry climates.

The solid desiccant cooling system operates on the principle of adsorption of water vapor from air. Firstly moisture is removed by a rotary desiccant wheel. The dried process air temperature is then lowered further to the desired room conditions using sensible heat exchangers and cooling coils. A DCS consists of four components, regeneration heat source, the rotary dehumidifier, sensible heat exchanger and the cooling unit [Figure 1][6].

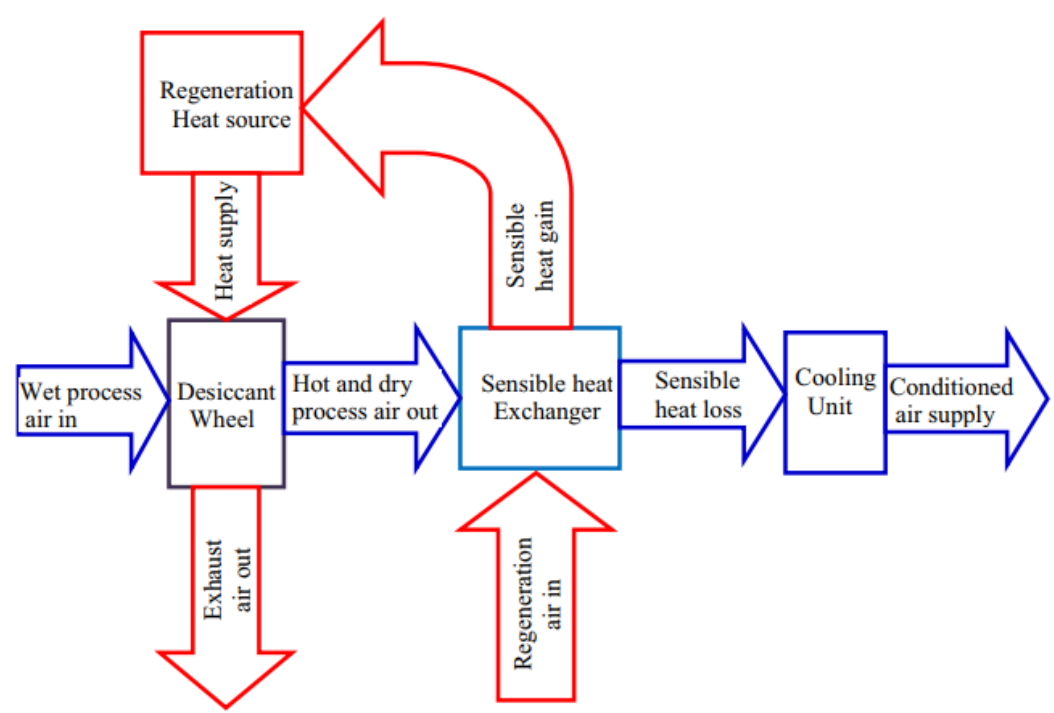

Figure 1 - Principle of solid desiccant cooling [22]

Several studies have been carried out on the desiccant cooling system by different researchers. Pennington [22] proposed the earliest desiccant cooling cycle by coupling the rotary desiccant dehumidifier with a heat source and evaporative cooler also known as the ventilation cycle. Then a modified form of Pennington cycle is designed to reuses the room return air as a dehumidifier process air inlet in hot and humid ambient conditions [18]. A similar cycle was proposed later by Dunkle [23] using a desiccant wheel. subsequently, Jurinak [24] has performed a simulated desiccant system by incorporating 
the component models into TRNSYS software. Uçkan et al. [25] presented the first experimental results of a based evaporative desiccant cooling system for hot and humid climatic conditions. The results showed that the ambient air can be cooled down to $19{ }^{\circ} \mathrm{C}$ from $31^{\circ} \mathrm{C}$ and a continuous supply of air at $25^{\circ} \mathrm{C}$ can be maintained to a conditioned space.

Further a simplified advanced solid desiccant cycle namely SENS cycle has been proposed [6], then a little modification over SENS cycle is done by replacing sensible heat exchanger, cooling tower and cooling coil with a pair of an indirect evaporative cooler and a direct evaporative cooler to avoid complexity and to simplify system configuration, which is called direct-indirect evaporative cooling (DINC) cycle, the thermal coefficient of performance of the DINC cycle has been obtained around 1.6. Kadoma et al. [18], investigated the impact of the desiccant wheel speed, air velocity and regeneration temperature on the coefficient of performance (COP).

A wide range of system simulation studies exist in literature. Ankit [26], performed a review study that draws attention to the principles of desiccant cooling systems through performance studies; through which its feasibility and merits of energy and costs saving in different climatic conditions have been proved. Merabti et al. [27], performed a simulation study of a solar-powered desiccant evaporative cooling system. The results show that the system can control the moisture and thus offering acceptable comfort conditions, confirming that it is well suited for wet areas. Hatraf et al. [28], carried out a study to show the various factors as the dehumidification rate, the generation temperature then the rotary heat exchanger and evaporative cooler efficiencies influence the efficiency of a solid desiccant system by using TRNSYS software. The results indicated that such a system is efficient for reducing the uncomfortable water content in the air. Consequently, desiccant evaporative cooling offers a promising alternative to conventional air conditioning systems for climates with a high latent load.

The objective of the present work is to improve the performance of the ventilation cycle of a desiccant evaporative cooling system using direct/indirect evaporative cooler. New configuration is proposed and compared with the conventional cycle and E. Elgendy et al.[29] previous studied evaporative cooling system configurations. The proposed system has included extra heat recovery wheels to improve the performance of the ventilation desiccant system. Simulation models have been developed for all configurations. Then all the obtained results concerning performance characteristics are investigated for conventional, previous systems under various ambient temperature and humidity ratio, and then validated with the available literature data. As the main aim of the study is to develop the performance of the desiccant evaporative cooling system, performance characteristics are also performed for the proposed system under various 
ambient temperature and humidity ratio and compared to conventional and previous systems.

\section{System configurations description}

Four fundamental components form the main structure of the conventional desiccant cooling system; desiccant wheel, rotating heat exchanger, evaporative cooler, and regeneration heat exchanger. In the present work, four system configurations operating in ventilation mode, conventional desiccant cooling system, previously proposed system (system A and system B) and new proposed system (system C) are illustrated in a schematic diagram as shown in [Figure 2-5]. All systems have two main air streams, the first stream is the process air stream represented as state points 1 to 4 , while the second stream is the regeneration stream represented as state points 5 to 9 .

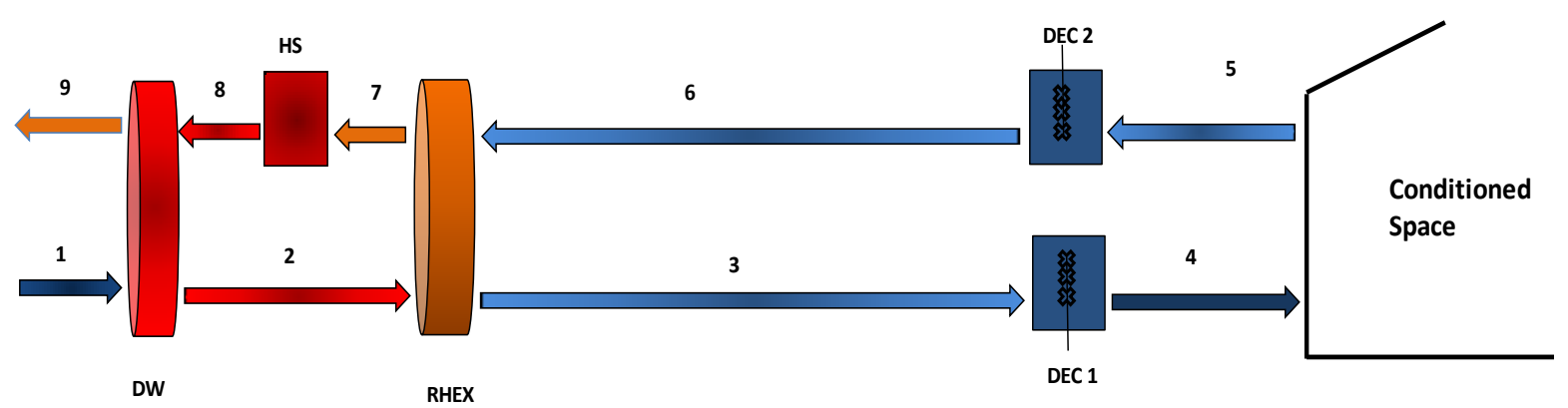

Figure 2- Conventional Cycle

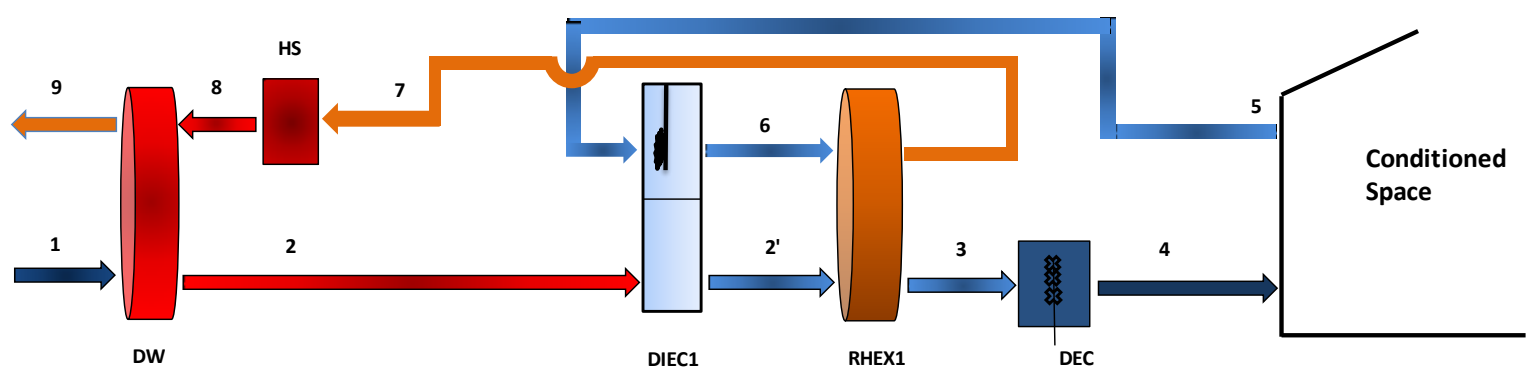

Figure 3 - System A

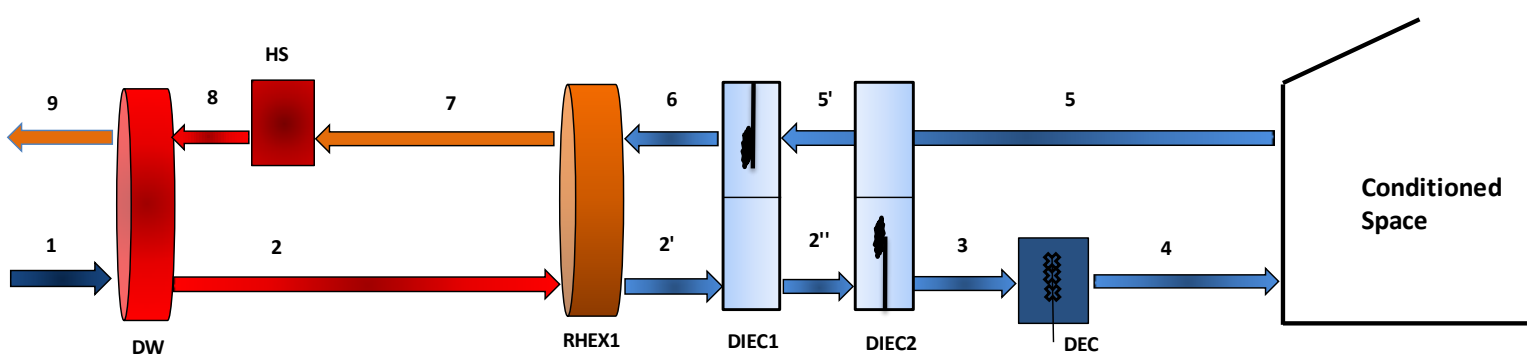

Figure 4 - System B 


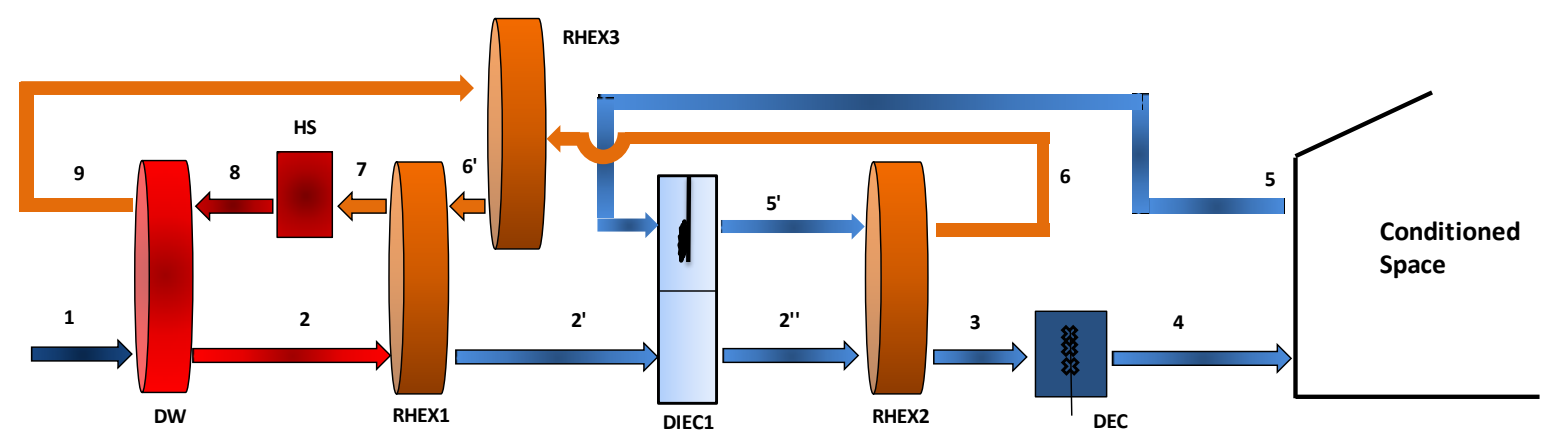

Figure 5 - System C

The solid desiccant cooling system operates on the principle of adsorption of water vapor from air. In the conventional system, the moisture in the ventilated process air stream is first removed by a rotating desiccant wheel (DW) (1-2). The temperature of this dried process air is then lowered sensibly through a rotating heat exchanger (RHEX) (2-3). Then the process air is cooled to supply the desired room conditions by passing through a direct evaporative cooler (DEC-1) (3-4) which results in a decrease in temperature and restores acceptable humidity. To make the system working continually, amount of water vapor adsorbed by the rotating desiccant wheel must be driven out of the desiccant material so that it can be dried enough (regenerated) to absorb water vapor in the next cycle thus through regeneration air stream, return air at state 5 is cooled and humidified in another direct evaporative cooler (DEC-2) (5-6). Afterward, the air passes through a rotating heat exchanger leading to the heat to be transferred from the process to the regeneration air stream (6-7). With the assistance of a heat source, the air is further heated to reach the required regeneration temperature (7-8), therefore this heated air is used to regenerate the desiccant wheel, and then hot and humid air is exhausted at point 9.

Concerning configuration-1, a direct/indirect evaporative cooler (DIEC) is added before the rotating heat exchanger for further cooling of the process air (2-2'). However, in configuration-3, two extra direct/indirect evaporative coolers (DIEC-1) (DIEC-2) are installed before (DEC) in an opposite manner. Thus leading to the process air is directly evaporative cooled in the (DIEC-2) (2'-3). Regarding configuration-5, to improve the heat recovery process, two extra heat recovery wheels are added for configuration-1, one before (DIEC) and the other before heat source (HS). 


\section{Methodology}

System simulations are performed using TRNSYS. Component models utilized in TRNSYS are type-683, type-760, type-506 and type-757 to simulate a rotary desiccant dehumidifier, rotating heat exchanger, direct evaporative cooler and direct/indirect evaporative cooler respectively. Dry bulb temperature and humidity ratio are obtained from the TRNSYS model for all points of air inlet and outlet.

TRNSYS simulation models for conventional cycle, previously-studied configurations by E. Elgendy et al.[29], and the present proposed system are performed with assuming the below conditions:

- System operation is steady without air leakage or pressure drop through the process and regeneration air streams.

- Desiccant wheel effectiveness $\mathrm{F} 1=0.08$ and $\mathrm{F} 2=0.85$.

- DICs' and DIECs' effectiveness are 0.85 and 0.7 respectively.

- Rotary heat recovery wheel effectiveness is 0.85 .

The space cooling capacity $\left(Q_{\text {cool }}\right)$, air handling capacity (rate of heat removed $\left(Q_{d}\right)$ from the process air from state 1 to state 4$)$ and regeneration energy rate $\left(Q_{\text {reg }}\right)$ can be determined as follows, considering air properties at inlet and exit for each component in all the studied systems:

$\mathrm{Q}_{\text {cool }}=\dot{\mathrm{m}}_{\mathrm{a}}\left(\mathrm{h}_{5}-\mathrm{h}_{4}\right)$

$\mathrm{Q}_{\mathrm{d}}=\dot{\mathrm{m}}_{\mathrm{a}}\left(\mathrm{h}_{1}-\mathrm{h}_{4}\right)$

$\mathrm{Q}_{\text {reg }}=\dot{\mathrm{m}}_{\mathrm{a}}\left(\mathrm{h}_{8}-\mathrm{h}_{7}\right)$

Where $\left(\dot{m}_{\mathrm{a}}\right)$ refers to the air mass flow rate, while $(\mathrm{h})$ is the specific enthalpy at different state points. The thermal coefficient of performance $\left(\mathrm{COP}_{\mathrm{th}}\right)$ and air handling coefficient of performance $\left(\mathrm{COP}_{d}\right)$ can assess the performance of the desiccant evaporative cooling system. $\mathrm{COP}_{\text {th }}$ is defined as the ratio of space cooling capacity to the regeneration energy rate, which can be determined as:

$\mathrm{COP}_{\text {th }}=\frac{\mathrm{Q}_{\text {cool }}}{\mathrm{Q}_{\text {reg }}}=\frac{\dot{\mathrm{m}}_{\mathrm{a}}\left(\mathrm{h}_{5}-\mathrm{h}_{4}\right)}{\dot{\mathrm{m}}_{\mathrm{a}}\left(\mathrm{h}_{8}-\mathrm{h}_{7}\right)}$ 
While $\mathrm{COP}_{\mathrm{d}}$ is described as the ratio of the rate of air handling capacity to the required regeneration energy rate and can be estimated as:

$\operatorname{COP}_{\mathrm{d}}=\frac{\mathrm{Q}_{\mathrm{d}}}{\mathrm{Q}_{\mathrm{reg}}}=\frac{\dot{\mathrm{m}}_{\mathrm{a}}\left(\mathrm{h}_{1}-\mathrm{h}_{4}\right)}{\dot{\mathrm{m}}_{\mathrm{a}}\left(\mathrm{h}_{8}-\mathrm{h}_{7}\right)}$

Carnot coefficient of performance $\left(\mathrm{COP}_{\mathrm{c}}\right)$ is the maximum possible $\mathrm{COP}$ for a reversible system under given operating conditions. Carnot coefficient of performance for the reversible desiccant evaporative cooling system can be presented as, [29]:

$\operatorname{COP}_{c}=\operatorname{COP}_{c, r} \eta_{c, h e}=\left[\frac{T_{c s}}{T_{a m b}-T_{c s}}\right]\left[\frac{T_{a m b}}{T_{s o r}}\right]$

Where $\left(\eta_{c, h e}\right)$ is the thermal efficiency of Carnot heat engine and $\left(\mathrm{COP}_{\mathrm{c}, \mathrm{r}}\right)$ is the coefficient of performance for Carnot refrigerator. In the desiccant evaporative cooling system, the temperature of the ambient and conditioned space are $\mathrm{T}_{1}$ and $\mathrm{T}_{5}$, respectively, and the temperature of the heating source may be taken to be regeneration temperature $T_{8}$. Then, Eq. (6) can be written as:

$\operatorname{COP}_{c}=\left[1-\frac{\mathrm{T}_{1}}{\mathrm{~T}_{8}}\right]\left[\frac{\mathrm{T}_{5}}{\mathrm{~T}_{1}-\mathrm{T}_{5}}\right]$

The exergy efficiency of the desiccant evaporative cooling system is defined as:

$\eta_{\text {ex }}=\frac{\dot{\mathrm{E}}_{\text {cool }}}{\grave{\mathrm{E}}_{\mathrm{reg}}}=1-\frac{\dot{\mathrm{E}}_{\mathrm{des}, \text { tot }}}{\dot{\mathrm{E}}_{\mathrm{reg}}} \quad$ Or $\quad \eta_{\mathrm{ex}}=\frac{\mathrm{COP}_{\text {th }}}{\operatorname{COP}_{\mathrm{c}}}$

\section{Results and discussions}

In the present work, proposed system configuration in addition to the conventional system and previously proposed systems are examined and investigated over an extensive range of ambient air conditions. Firstly, the ambient air temperature is varied from 30 to $40{ }^{\circ} \mathrm{C}$, while ambient air humidity is held constant at $0.015 \mathrm{kgv} / \mathrm{kga}$. Secondly, in order to imitate the climatic weather circumstances of coastal Egyptian cities, ambient air humidity is varied from 0.01 to $0.02 \mathrm{kgv} / \mathrm{kga}$, while the temperature is held constant at $35^{\circ} \mathrm{C}$. During the whole investigation, air mass flow rates for both Process and regeneration air streams are kept constant at $1 \mathrm{~kg} / \mathrm{s}$. 


\subsection{Model validation}

The simulation model is developed for a conventional desiccant evaporative cooling system, and then the results obtained are compared to experimental data reported by Kodama et al. [30] and predicted results reported by Elgendy et al. [29]. All air state points of process and regeneration air streams for the present work, Elgendy et al. [29] and Kodama et al. [30] are listed in [Table-1]. The present work indicated a good agreement with the predicted data, accompanied by an average error of $1.59 \%$ and $0.65 \%$ for air temperature and humidity respectively. Also, the present work recorded a good agreement with experimental data, accompanied by an average error of $3.14 \%$ and $2.32 \%$ for air temperature and humidity respectively.

Table 1 - Comparison between present work and literature reported data

\begin{tabular}{|c|c|c|c|c|c|c|c|c|c|c|}
\hline \multicolumn{4}{|c|}{ Ambient air temperature } & \multicolumn{2}{|r|}{$35\left({ }^{\circ} \mathrm{C}\right)$} & & & & & \\
\hline \multicolumn{4}{|c|}{ Ambient air humidity ratio } & \multicolumn{2}{|r|}{0.0110} & & & & & \\
\hline \multicolumn{4}{|c|}{ Effectiveness of H.R.H.EX } & \multicolumn{2}{|r|}{0.8} & & & & & \\
\hline \multicolumn{4}{|c|}{ Effectiveness of DEC-1 and DEC-2 } & \multicolumn{2}{|r|}{0.85} & & & & & \\
\hline \multirow[t]{2}{*}{ Point } & \multicolumn{5}{|c|}{ Dry bulb Temperaure $\left({ }^{\circ} \mathrm{C}\right)$} & \multicolumn{5}{|c|}{ Humidity ratio $\left(\mathrm{kg}_{\mathrm{v}} \mathrm{kg}_{\mathrm{a}}{ }^{-1}\right)$} \\
\hline & $\begin{array}{l}\text { Present } \\
\text { Work }\end{array}$ & $\begin{array}{l}\text { Elgendy et } \\
\text { al. (2015) }\end{array}$ & Error(\%) & $\begin{array}{l}\text { Kodama et } \\
\text { al. (2001) }\end{array}$ & Error(\%) & Present Work & $\begin{array}{l}\text { Elgendy et } \\
\text { al. (2015) }\end{array}$ & Error(\%) & $\begin{array}{l}\text { Kodama et } \\
\text { al. (2001) }\end{array}$ & Error(\%) \\
\hline 2 & 57.93 & 56.50 & $2.54 \%$ & 55.50 & $4.39 \%$ & 0.0044140 & 0.0044 & $0.32 \%$ & 0.00440 & $0.32 \%$ \\
\hline 3 & 25.27 & 25.00 & $1.09 \%$ & 24.80 & $1.90 \%$ & 0.0044140 & 0.0044 & $0.32 \%$ & 0.00448 & $1.47 \%$ \\
\hline 4 & 14.92 & 14.79 & $0.85 \%$ & 14.50 & $2.87 \%$ & 0.0086317 & 0.0086 & $0.37 \%$ & 0.00920 & $6.18 \%$ \\
\hline 5 & 26.00 & 26.00 & -- & 26.00 & -- & 0.0100000 & 0.0100 & -- & 0.01000 & -- \\
\hline 6 & 19.46 & 19.45 & $0.04 \%$ & 20.00 & $2.71 \%$ & 0.0127063 & 0.0127 & $0.05 \%$ & 0.01280 & $0.73 \%$ \\
\hline 7 & 51.64 & 50.45 & $2.36 \%$ & 51.00 & $1.26 \%$ & 0.0127063 & 0.0127 & $0.05 \%$ & 0.01250 & $1.65 \%$ \\
\hline 8 & 75.34 & 78.80 & $4.38 \%$ & 80.00 & $5.82 \%$ & 0.0127063 & 0.0127 & $0.05 \%$ & 0.01250 & $1.65 \%$ \\
\hline 9 & 52.54 & 53.32 & $1.46 \%$ & 56.00 & $6.17 \%$ & 0.0192923 & 0.0201 & $4.02 \%$ & 0.01810 & $6.59 \%$ \\
\hline
\end{tabular}

\subsection{Ambient air temperature variation effect}

Performance characteristics are affected by the variation of ambient air temperature, as represented in figures 6-12. The Psychometric process [Figure-6] is executed to illustrate and discuss the impact of different air temperatures on the conventional system. It is observed that when ambient temperature and enthalpy increases state point (1), all air state points temperatures increase consequently with different rates in the air process stream. Conditions of exit air from conditioned space are kept constant at $26{ }^{\circ} \mathrm{C}$ dry bulb temperature and $0.01 \mathrm{kgv} / \mathrm{kga}$ humidity ratio state point (5). Concerning the space cooling capacity, calculated from specific enthalpy difference between state points (4-5) at constant mass flow rate condition, decreases as supply air temperature increases due to the increase in the ambient specific enthalpy. Consequently Thermal coefficient of performance, calculated as the ratio of space cooling capacity state points (4- 
5) to regeneration energy rate state points (7-8) at constant mass flow rate condition, decreases as ambient specific enthalpy rises. On the other hand, air handling capacity, defined as specific enthalpy difference between ambient condition state point (1) and conditioned space air supply state point (4) at constant mass flow rate condition, have a directly proportional relationship with ambient condition-specific enthalpy. Also, air handling COP, obtained from the ratio of air handling capacity to regeneration energy rate at constant mass flow rate condition, increases with the increment of the ambient specific enthalpy. Therefore, the regeneration energy, described as the difference between specific enthalpies of state points (7-8) at constant mass flow rate, rises as a result of the increase in the specific enthalpy of the supply condition.



\section{Figure 6 - Psychometric process of the conventional system at different ambient air temperatures}

Variation of space cooling capacity with ambient air temperature described in [Figure-7] for all systems. It is clear that air handling capacity is inversely proportional with temperature raise from 30 to $40{ }^{\circ} \mathrm{C}$ as space cooling capacity decreased by $14.6 \%$, $4.0 \%, 4.5 \%$ and $2.8 \%$ for the conventional system, system $\mathrm{A}$, system B, and system $\mathrm{C}$ respectively, noted that system $\mathrm{C}$ has the lowest drop in space cooling capacity regarding to temperature increase. Moreover, the average space cooling capacity of system $\mathrm{C}$ is greater than the conventional system, system A, and system B by $54.8 \%, 5.6 \%$, and $14.1 \%$ respectively. 


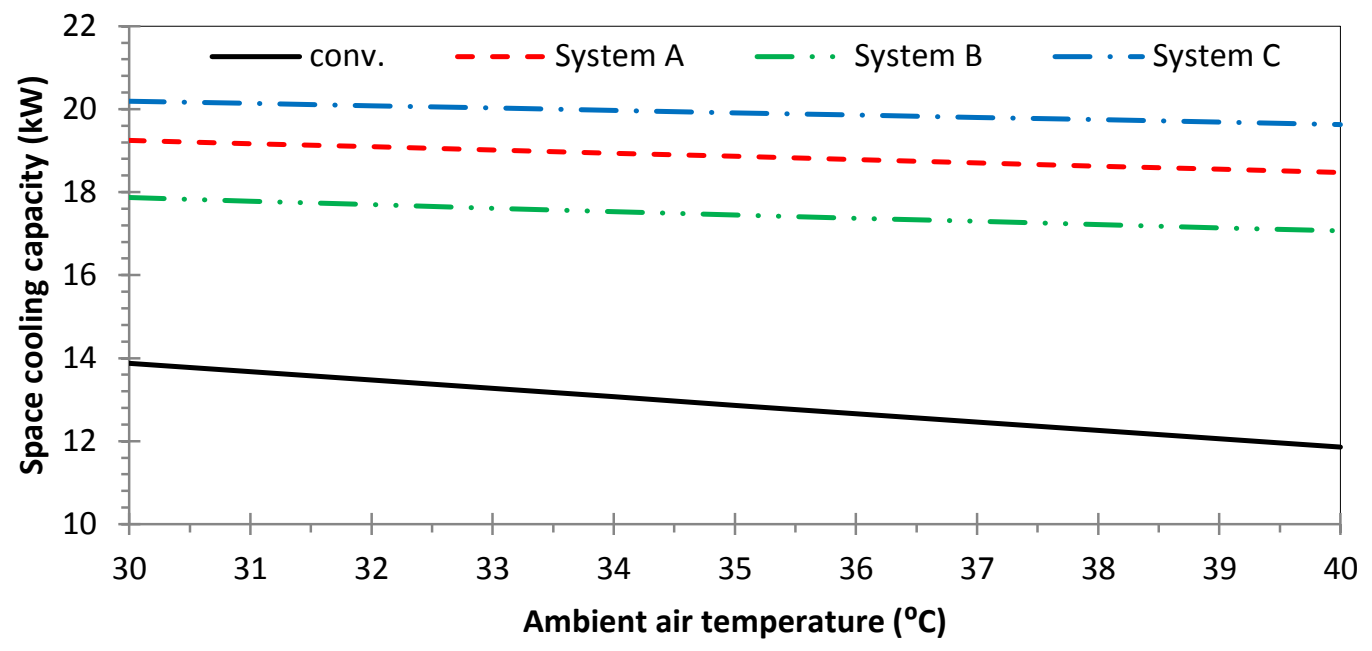

Figure 7 - Variation of space cooling capacity with ambient air temperature for all systems

Relating to ambient air temperature raise impact on air handling capacity, [Figure8] illustrates that air handling capacity increases as ambient air temperature increases for all systems. As ambient air temperature increases from 30 to $40{ }^{\circ} \mathrm{C}$ air handling capacity increases by $27.0 \%, 26.5 \%, 27.4 \%$ and $26.4 \%$ for the conventional system, system A, system $\mathrm{B}$, and system $\mathrm{C}$ respectively. Besides system $\mathrm{C}$ air handling capacity exceeds the conventional system, system A, and system B by $20.2 \%, 2.6 \%$, and $6.2 \%$ respectively.

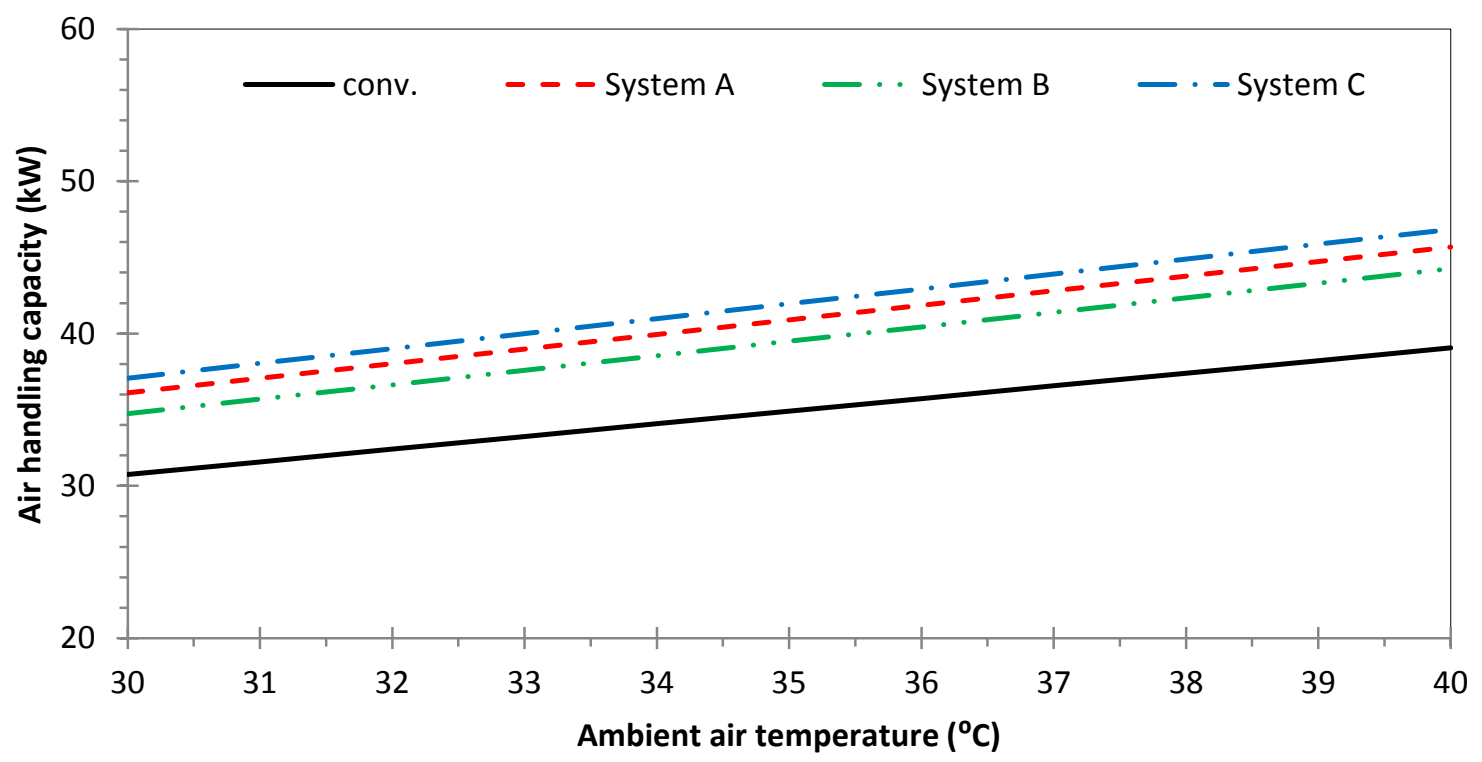

Figure 8 - Ambient air temperature raise impact on air handling capacity for all systems 


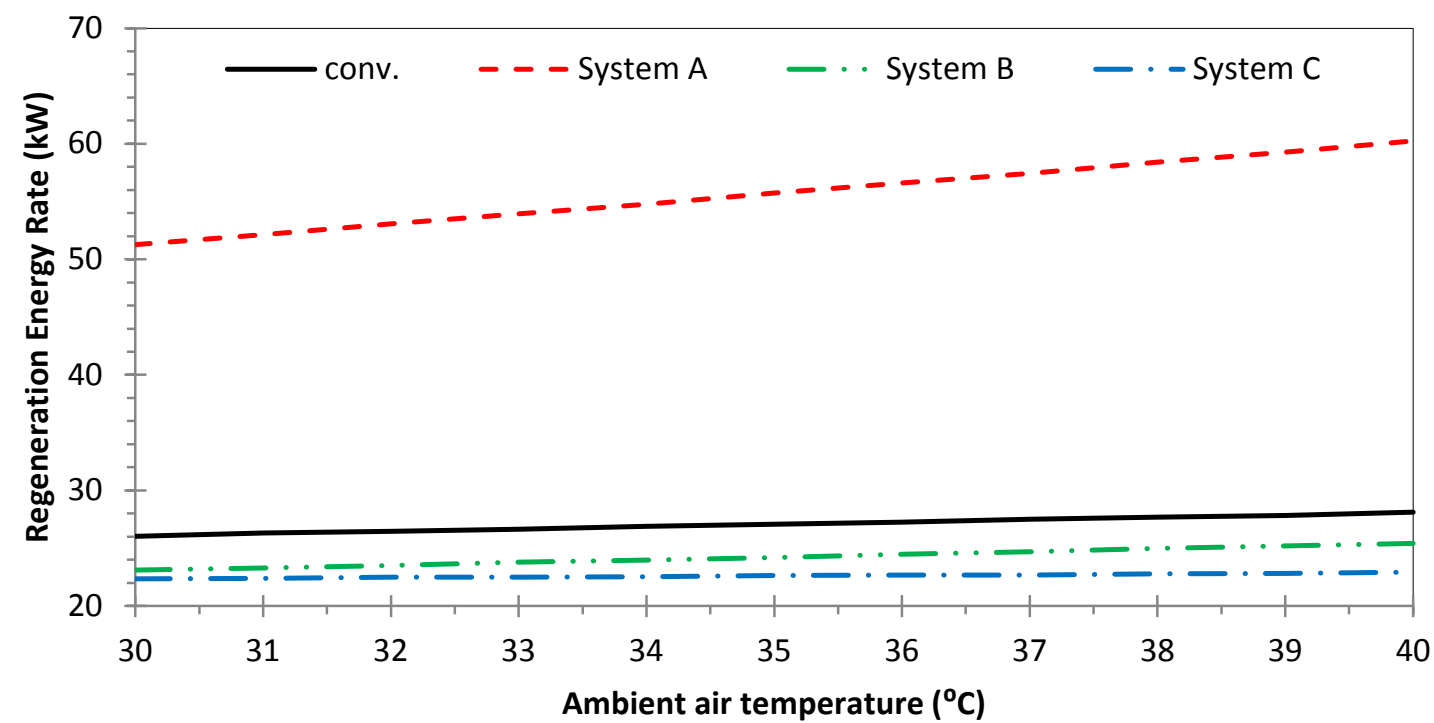

Figure 9 - Effect of ambient air temperature variation on the regeneration energy rate for all systems

The effect of ambient air temperature variation on the regeneration energy rate is shown in [Figure-9]. Regeneration energy has a directly proportional relationship with ambient air temperature. As ambient air temperature increase from 30 to $40{ }^{\circ} \mathrm{C}$ regeneration energy rate increases by $8.0 \%, 17.5 \%, 10.0 \%$, and $2.6 \%$ for the conventional system, system $\mathrm{A}$, system $\mathrm{B}$, and system $\mathrm{C}$ respectively, with taking into account that system $\mathrm{C}$ recorded the lowest raise of the regeneration energy rate. Furthermore, system $\mathrm{C}$ has the lowest required regeneration energy rate by $16.5 \%, 59.4 \%$, and $6.7 \%$ from the conventional system, system A, and system B respectively.

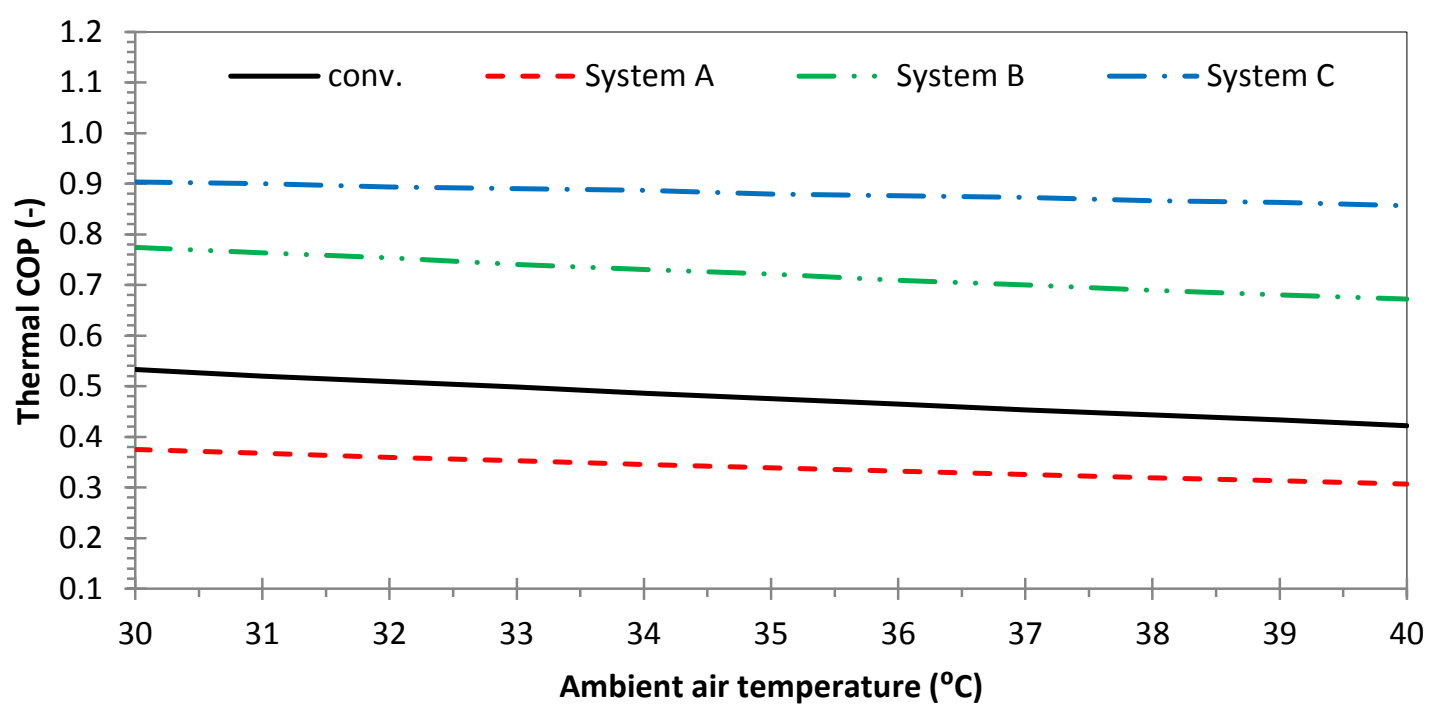

Figure 10 - Influence of ambient air temperature on thermal COP for all systems 
[Figure-10] illustrates the influence of ambient air temperature on thermal COP, obviously the raising of ambient air temperature from 30 to $40{ }^{\circ} \mathrm{C}$ leads to the drop of thermal COP by $20.9 \%, 18.3 \%, 13.1 \%$ and $5.2 \%$ for the conventional system, system A, system $\mathrm{B}$, and system $\mathrm{C}$ respectively. Additionally, thermal COP of system $\mathrm{C}$ has the greatest value over the conventional system, system A and system B by $85.0 \%, 159.4 \%$, and $22.1 \%$ respectively.

Variation of air handling COP with ambient air temperature described in [Figure11] for all systems, clearly the air handling COP is directly proportional to ambient air temperature. As ambient air temperature varies from 30 to $40{ }^{\circ} \mathrm{C}$, the air handling COP increase by $17.7 \%, 7.7 \%, 15.9 \%$, and $23.2 \%$ for the conventional system, system A, system $\mathrm{B}$, and system $\mathrm{C}$ respectively, in addition system $\mathrm{C}$ air handling COP exceeds the conventional system, system A and system B by $44.0 \%, 152.9 \%$, and $14.0 \%$ respectively.



Figure 11 - Variation of air handling COP with ambient air temperature for all systems

Regarding the exergetic efficiency of all configurations, [Figure-12] illustrates that exergetic efficiency increases as ambient air temperature increases for all systems. As ambient air temperature increase from 30 to $40{ }^{\circ} \mathrm{C}$ exergetic efficiency increases by $172.0 \%, 181.1 \%, 196.5 \%$, and $226.1 \%$ for the conventional system, system A, system B, and system $\mathrm{C}$ respectively. Furthermore, system $\mathrm{C}$ exergetic efficiency exceeds the conventional system, system A and system B by $86.6 \%, 163.7 \%$, and $15.5 \%$ respectively. 


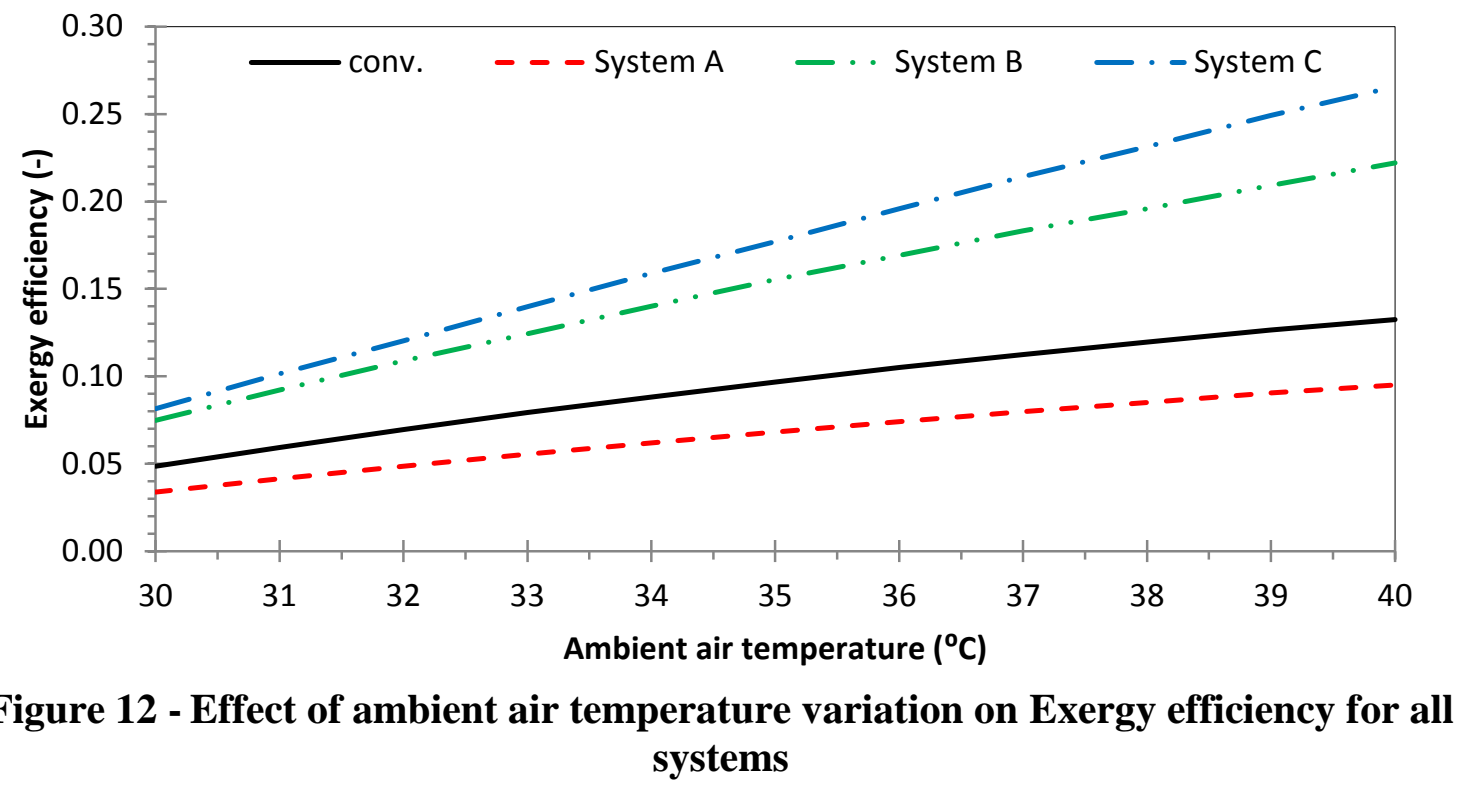

\subsection{Ambient air humidity ratio Variation effect}

Performance characteristics are affected by the variation of ambient air humidity ratio and can be represented in Figures from 13 to 19. Psychometric process [Figure-13] created to illustrate and discuss the impact of different air humidity ratios on the conventional system at constant dry-bulb temperature $35^{\circ} \mathrm{C}$. It is observed that when ambient humidity ratio increases state point (1), all temperature and specific enthalpy increase consequently with different rates in the air process stream. Conditions of exit air from conditioned space are kept constant at $26{ }^{\circ} \mathrm{C}$ dry bulb temperature and $0.01 \mathrm{kgv} / \mathrm{kga}$ humidity ratio state point (5). With the reference to the space cooling capacity, calculated from specific enthalpy difference between state points (4-5) at constant mass flow rate condition, decreases as supply air humidity ratio increases due to the increase in the ambient specific enthalpy. Consequently Thermal coefficient of performance, calculated as the ratio of space cooling capacity state points (4-5) to Regeneration energy rate state points (7-8) at constant mass flow rate condition, decreases as ambient air humidity ratio increases. Diversely air handling capacity, defined as specific enthalpy difference between ambient condition state point (1) and conditioned space air supply state point (4) at constant mass flow rate condition, have a directly proportional relationship with ambient condition air humidity ratio. Also, air handling COP, defined as the ratio of air handling capacity to regeneration energy rate at constant mass flow rate condition, increases with the ambient specific enthalpy raise. Thus the regeneration energy, defined as the difference between the specific enthalpy of state points (7-8) at constant mass flow rate, rises due to the raise of the specific enthalpy of the supply condition. 


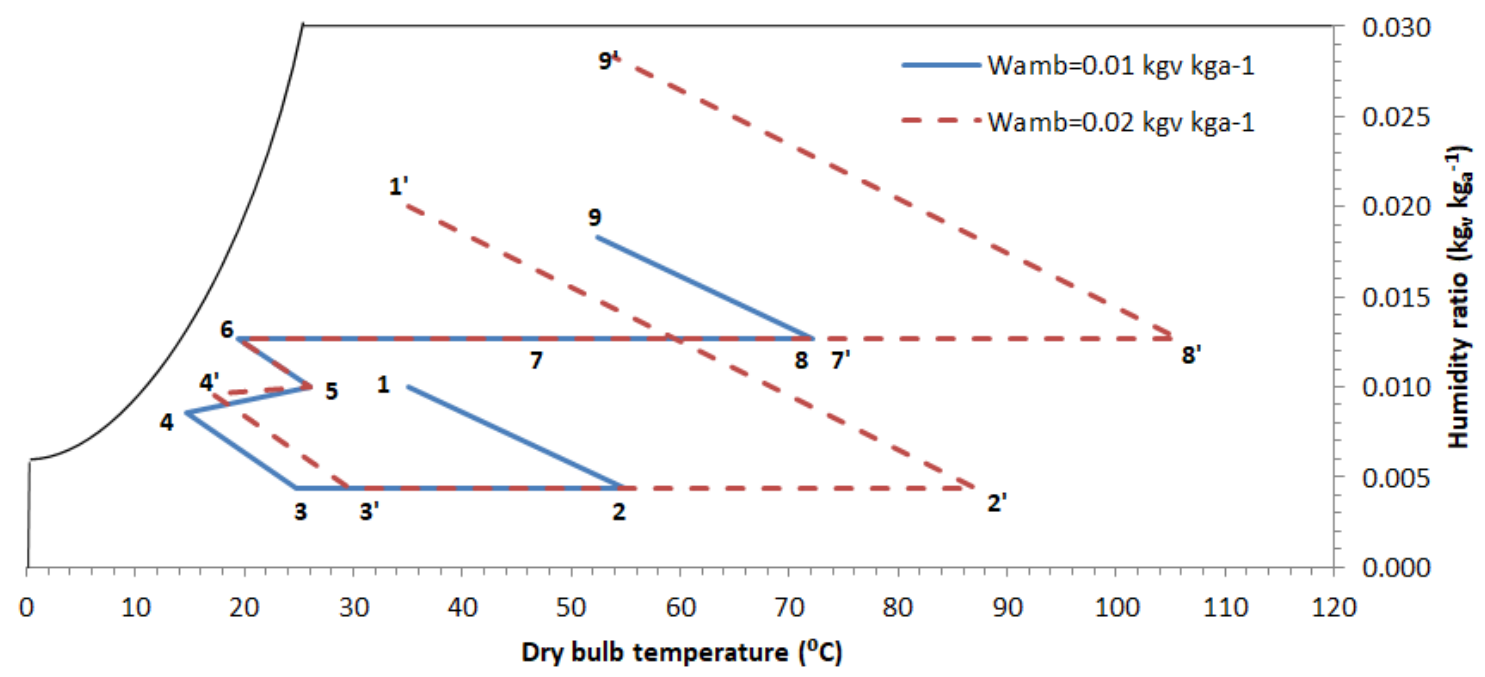

Figure 13 - Psychometric process of the conventional system at different ambient air humidity ratios

Variation of space cooling capacity with ambient humidity ratio is described in [Figure14] for all systems, and it appears that air handling capacity is inversely proportional with humidity ratio raise from $0.01 \mathrm{kgv} / \mathrm{kga}$ to $0.02 \mathrm{kgv} / \mathrm{kga}$ as space cooling capacity is decreased by $32.8 \%, 9.7 \%, 9.7 \%$, and $1.8 \%$ for the conventional system, system A, system $\mathrm{B}$, and system $\mathrm{C}$ respectively, noted that system $\mathrm{C}$ has the lowest drop in space cooling capacity regarding humidity ratio raise. Moreover, the average space cooling capacity of system $\mathrm{C}$ is greater than the conventional system, system A, and system B by $55.2 \%$, $5.6 \%$, and $14.1 \%$ respectively.

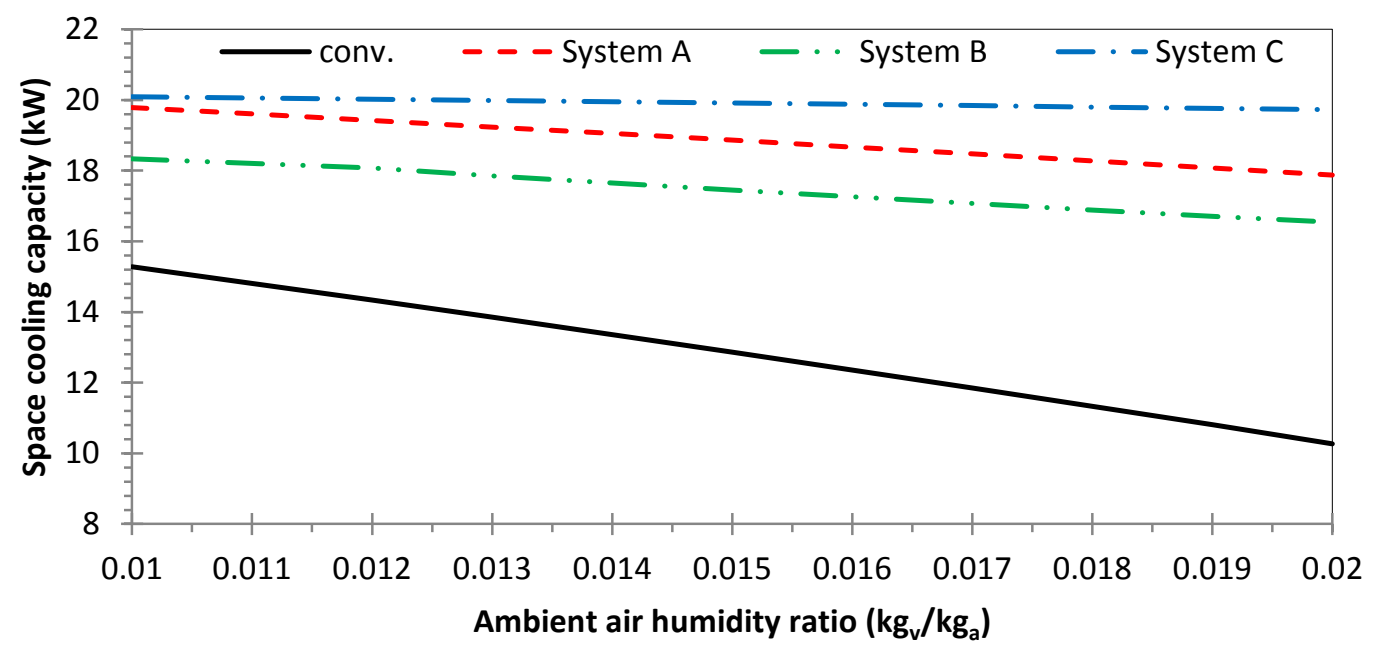

Figure 14 - Variation of space cooling capacity with ambient humidity ratio for all systems 




Figure 15 - Ambient air humidity ratio raise impact on air handling capacity for all systems

Relating to the impact of ambient air humidity ratio raise on air handling capacity, [Figure-15] illustrates that air handling capacity increases as ambient air humidity ratio increases for all systems. As ambient air humidity ratio increases from $0.01 \mathrm{kgv} / \mathrm{kga}$ to $0.02 \mathrm{kgv} / \mathrm{kga}$ air handling capacity increases by $84.2 \%, 81.8 \%, 86.6 \%$, and $86.2 \%$ for the conventional system, system A, system B, and system $\mathrm{C}$ respectively. Additionally, system $\mathrm{C}$ air handling capacity exceeds the conventional system, system A, and system B by $20.3 \%, 2.6 \%$, and $6.2 \%$ respectively.

The influence of ambient air humidity ratio variation on the regeneration energy rate is shown in [Figure-16]. Regeneration energy has a directly proportional relationship with ambient air humidity ratio. As ambient air humidity ratio increases from 0.01 $\mathrm{Kgv} / \mathrm{Kga}$ to $0.02 \mathrm{Kgv} / \mathrm{Kga}$ regeneration energy increased by $29.0 \%, 54.3 \%, 37.9 \%$, and $33.9 \%$ for the conventional system, system A, system B, and system C respectively, however system $\mathrm{C}$ recorded the lowest regeneration energy rate raise. Moreover, system $\mathrm{C}$ has the lowest required regeneration energy rate by $16.4 \%, 59.5 \%$ and $6.7 \%$ for the conventional system, system A, and system B respectively. 


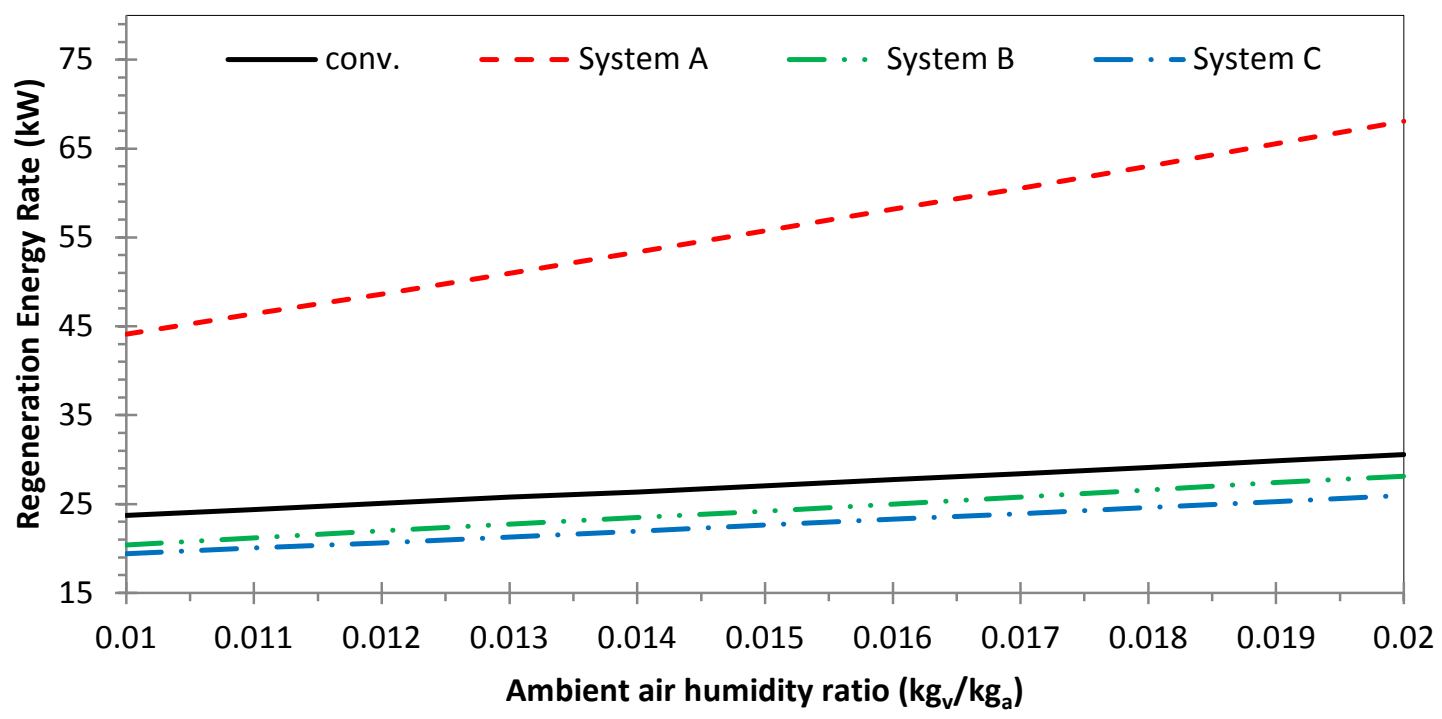

Figure 16 - Influence of ambient air humidity ratio variation on the regeneration energy rate for all systems

[Figure-17] illustrates the effect of ambient air humidity ratio on thermal COP, it is observed that raising of ambient air humidity ratio from $0.01 \mathrm{kgv} / \mathrm{kga}$ to $0.02 \mathrm{kgv} / \mathrm{kga}$ decreases the thermal COP by $47.9 \%, 41.5 \%, 34.5 \%$ and $26.7 \%$ for the conventional system, system $\mathrm{A}$, system $\mathrm{B}$, and system $\mathrm{C}$ respectively, with taking into consideration that the thermal $\mathrm{COP}$ of system $\mathrm{C}$ has the greatest value over the conventional system, system A, and system B by $84.4 \%, 157.0 \%$, and $21.6 \%$ respectively.



Figure 17 - Effect of ambient air humidity ratio on thermal COP for all systems 
The variation of air handling COP with ambient air humidity ratio described in [Figure-18] for all systems, and it is discerned that air handling COP is directly proportional to ambient air humidity ratio. As ambient air humidity ratio varied from 0.01 $\mathrm{kgv} / \mathrm{kga}$ to $0.02 \mathrm{kgv} / \mathrm{kga}$ the air handling COP increases by $42.8 \%, 17.8 \%, 35.4 \%$, and $39.1 \%$ for the conventional system, system $\mathrm{A}$, system $\mathrm{B}$, and system $\mathrm{C}$ respectively, in addition, system $\mathrm{C}$ air handling $\mathrm{COP}$ exceeds the conventional system, system $\mathrm{A}$, and system $\mathrm{B}$ by $43.9 \%, 152.5 \%$, and $13.8 \%$ respectively.

Regarding exergetic efficiency of all configurations, [Figure-19] illustrates that exergetic efficiency decreases as ambient air humidity ratio increases for all systems. As ambient air humidity ratio increases from $0.01 \mathrm{kgv} / \mathrm{kga}$ to $0.02 \mathrm{kgv} / \mathrm{kga}$ exergetic efficiency is decreased by $70.0 \%, 65.9 \%, 64.5 \%$, and $57.3 \%$ for the conventional system, system $\mathrm{A}$, system $\mathrm{B}$, and system $\mathrm{C}$ respectively. Moreover, system $\mathrm{C}$ exergetic efficiency exceeds the conventional system, system A, and system B by $78.8 \%, 153.9 \%$, and $11.8 \%$ respectively.

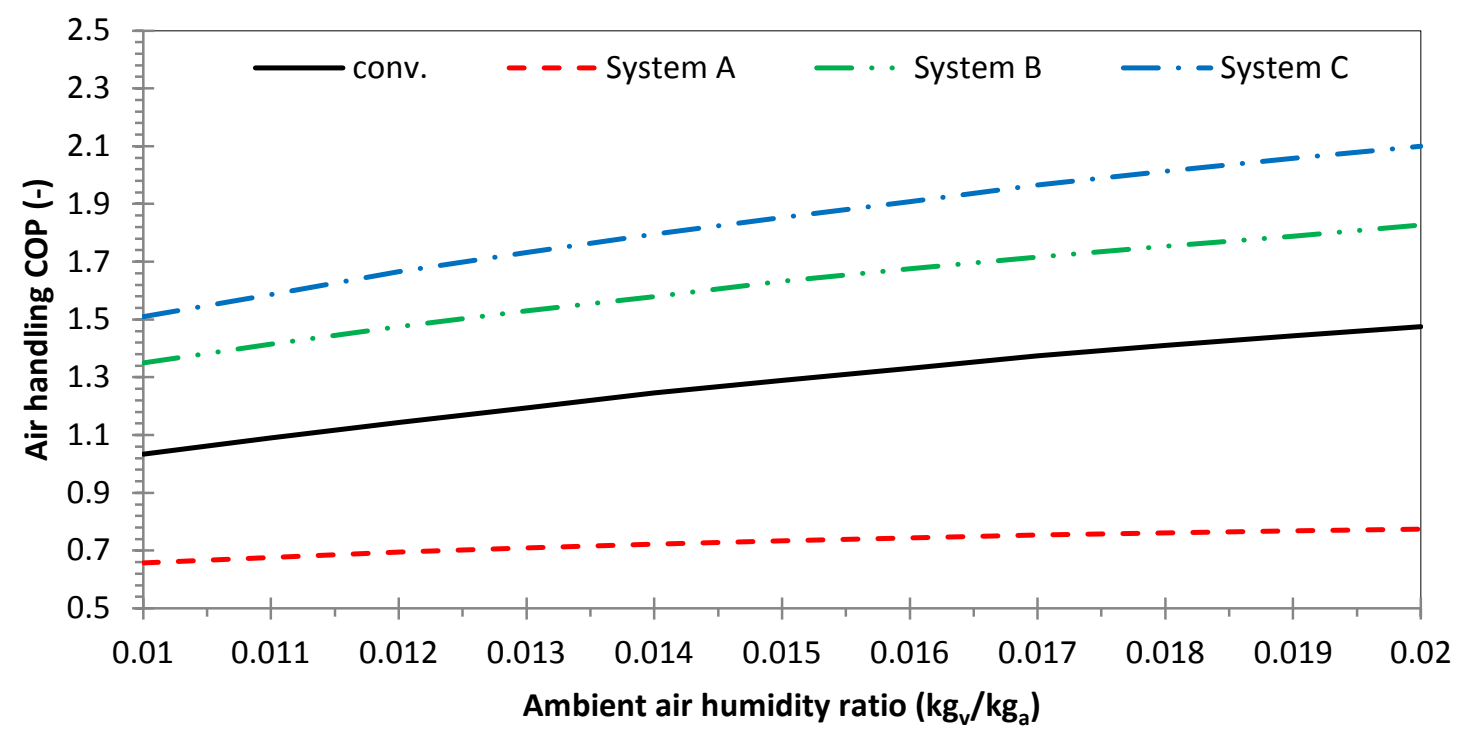

Figure 18 - Variation of air handling COP with ambient air humidity ratio for all systems 


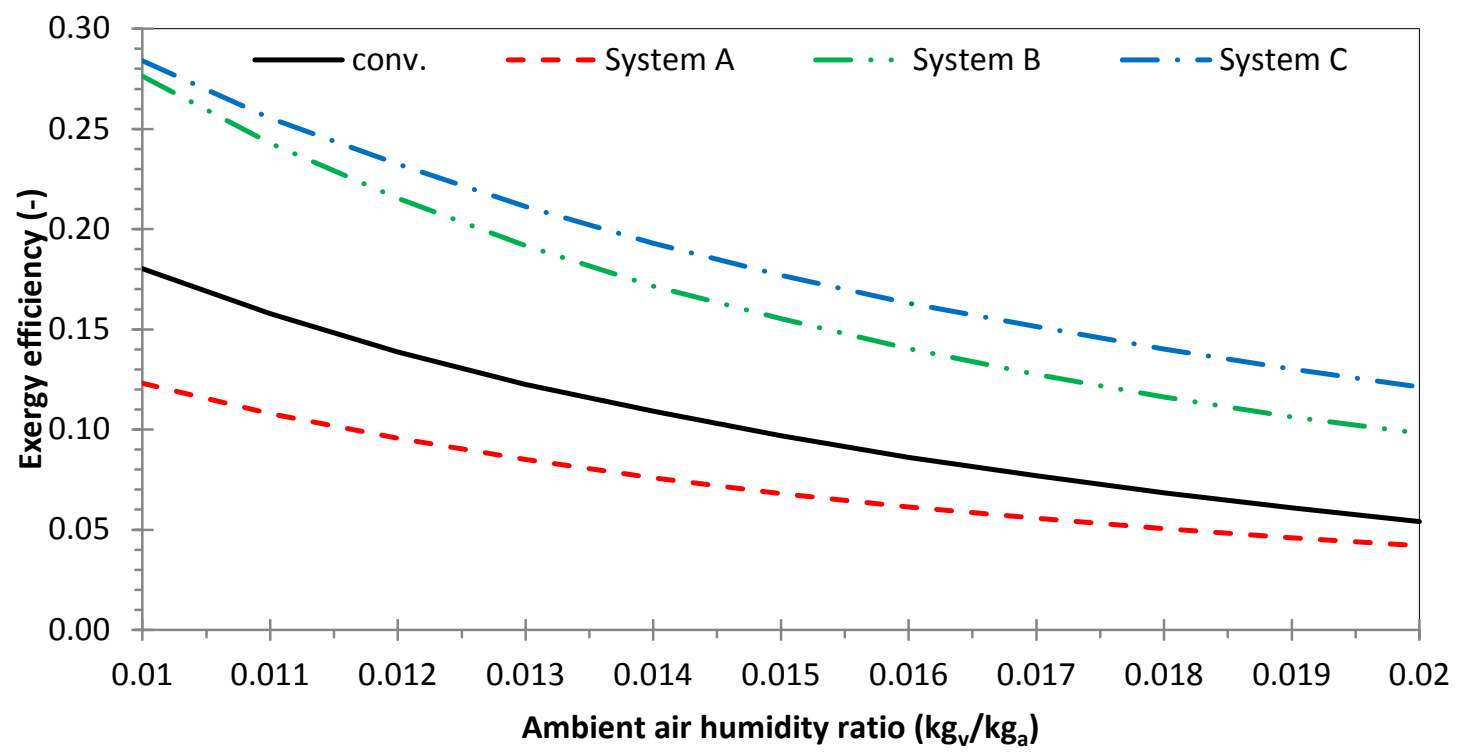

Figure 19 - Effect of ambient air temperature variation on Exergy efficiency for all systems

\section{Conclusion}

The present work improved the performance of the ventilation cycle of a desiccant evaporative cooling system using direct/indirect evaporative cooler and extra heat recovery wheels. The simulation results were in line with the published experimental data with average error of $3.14 \%$ and $2.32 \%$ for air temperature and humidity respectively, moreover indicated a good agreement with the predicted data of E. Elgendy et al. [29] conventional cycle and recorded an average error of $1.59 \%$ and $0.65 \%$ for air temperature and humidity respectively. The new proposed configuration compared with the conventional cycle and E. Elgendy et al. [29] previous studied evaporative cooling system configurations through various range of ambient temperature and humidity ratio and it was concluded that:

- The addition of direct/indirect evaporative coolers increased the air handling COP and adding extra heat recovery wheels decreased the regeneration energy rate.

- System $\mathrm{C}$ recorded the highest COP characteristics over the conventional cycle and previously proposed configurations during variation of both ambient temperature and humidity.

- System $\mathrm{C}$ average exergetic efficiency exceeded the conventional system, system A, and system B by $88.1 \%, 164.1 \%$, and $19.7 \%$ respectively. 


\section{References}

[1] A. Al-Alili, Y. Hwang, R. Radermacher, and I. Kubo, "A high efficiency solar air conditioner using concentrating photovoltaic/thermal collectors," Appl. Energy, vol. 93, pp. 138-147, 2012.

[2] M. Kashif Shahzad, M. Ali, N. Ahmed Sheikh, G. Qadar Chaudhary, M. Shahid Khalil, and T. U. Rashid, "Experimental evaluation of a solid desiccant system integrated with cross flow Maisotsenko cycle evaporative cooler," Appl. Therm. Eng., vol. 128, pp. 1476-1487, 2018.

[3] I. E. Agency, "The Future of Cooling. Opportunities for energy-efficient air conditioning.," Pop. Sci., vol. 7, no. 3, pp. 319-321, 2013.

[4] Griffin JP, "Montreal protocol on substances that deplete the ozone layer," Int. lawyer, p. 1261.

[5] IPCC, "Climate change 2007: the physical science basis," Intergov. Panel Clim. Chang., vol. 446, no. 7137, pp. 727-8, 2007.

[6] D. B. Jani, M. Mishra, and P. K. Sahoo, "Solid desiccant air conditioning - A state of the art review," Renew. Sustain. Energy Rev., vol. 60, pp. 1451-1469, 2016.

[7] O. Labban, T. Chen, A. F. Ghoniem, J. H. Lienhard, and L. K. Norford, "Nextgeneration HVAC: Prospects for and limitations of desiccant and membranebased dehumidification and cooling," Appl. Energy, vol. 200, pp. 330-346, 2017.

[8] W. Gao, W. Worek, V. Konduru, and K. Adensin, "Numerical study on performance of a desiccant cooling system with indirect evaporative cooler," Energy Build., vol. 86, pp. 16-24, 2015.

[9] I. Uçkan, T. Yilmaz, E. Hürdoğ an, and O. Büyükalaca, "Exergy analysis of a novel configuration of desiccant based evaporative air conditioning system," Energy Convers. Manag., vol. 84, pp. 524-532, 2014.

[10] J. Zhu and W. Chen, "A novel multivariate linear prediction model for the marine rotary desiccant air-conditioning by adding a dynamic correction factor," Appl. Therm. Eng., vol. 78, pp. 101-109, 2015.

[11] A. Kodama, N. Watanabe, T. Hirose, M. Goto, and H. Okano, "Performance of a multipass honeycomb adsorber regenerated by a direct hot water heating," Adsorption, vol. 11, no. 1 SUPPL., pp. 603-608, 2005.

[12] T. S. Ge, F. Ziegler, R. Z. Wang, and H. Wang, "Performance comparison between a solar driven rotary desiccant cooling system and conventional vapor compression system (performance study of desiccant cooling)," Appl. Therm. Eng., vol. 30, no. 6-7, pp. 724-731, 2010.

[13] A. Al-Alili, Y. Hwang, and R. Radermacher, "Review of solar thermal air conditioning technologies," Int. J. Refrig., vol. 39, pp. 4-22, 2014.

[14] T. K. Kassem, A. S. Alosaimy, A. M. Hamed, and M. Fazian, "Solar Powered Dehumidification Systems Using Desert Evaporative Coolers: Review,” Int. J. 
Eng. Adv. Technol., vol. 3, no. 1, pp. 115-128, 2013.

[15] G. Panaras, E. Mathioulakis, and V. Belessiotis, "Solid desiccant airconditioning systems - Design parameters," Energy, vol. 36, no. 5, pp. 23992406, 2011.

[16] S. Misha, S. Mat, M. H. Ruslan, and K. Sopian, "Review of solid/liquid desiccant in the drying applications and its regeneration methods," Renew. Sustain. Energy Rev., vol. 16, no. 7, pp. 4686-4707, 2012.

[17] Y. Abbassi, E. Baniasadi, and H. Ahmadikia, "Comparative performance analysis of different solar desiccant dehumidification systems," Energy Build., vol. 150, pp. 37-51, 2017.

[18] K. Daou, R. Z. Wang, and Z. Z. Xia, "Desiccant cooling air conditioning: A review," Renew. Sustain. Energy Rev., vol. 10, no. 2, pp. 55-77, 2006.

[19] D. La, Y. J. Dai, Y. Li, R. Z. Wang, and T. S. Ge, "Technical development of rotary desiccant dehumidification and air conditioning: A review," Renew. Sustain. Energy Rev., vol. 14, no. 1, pp. 130-147, 2010.

[20] A. Sohani and H. Sayyaadi, "Thermal comfort based resources consumption and economic analysis of a two-stage direct-indirect evaporative cooler with diverse water to electricity tariff conditions," Energy Convers. Manag., vol. 172, no. April, pp. 248-264, 2018.

[21] S. Moshari, G. Heidarinejad, and A. Fathipour, "Numerical investigation of wetbulb effectiveness and water consumption in one-and two-stage indirect evaporative coolers," Energy Convers. Manag., vol. 108, pp. 309-321, 2016.

[22] Pennington NA, "Humidity changer for air conditioning," USA Pat. No. 2, pp. $700,537,1955$.

[23] R. V Dunkle, Method of solar air conditioning, vol. MC1:1. 1965.

[24] J. J. Jurinak, Open Cycle Solid Desiccant Cooling: Component Models and System Simulations, no. v. 2. University of Wisconsin--Madison, 1982.

[25] H. E. ] Uçkan I, Yılmaz T, Büyükalaca O, "First experimental results of a desiccant based evaporative cooling system in Adana."

[26] A. Srivastav, "Performance studies for desiccant cooling system," pp. 405-408, 2016.

[27] L. Merabti, M. Merzouk, N. Kasbadji, N. Hatraf, and M. Abbas, "Rafraîchissement solaire par dessiccation," Rev. des Energies Renouvelables, vol. 17, pp. 3-403, 2014.

[28] M. M. Hatraf N, Merabti L, Kasbadji Merzouk N, Ouali M, "Preliminary study of desiccant cooling system under Algerian climates," Proc. I3CT-MENA, Tipaza, Alger., 2015.

[29] E. Elgendy, A. Mostafa, and M. Fatouh, "Performance enhancement of a desiccant evaporative cooling system using direct/indirect evaporative cooler," Int. J. Refrig., vol. 51, pp. 77-87, 2015.

[30] A. Kodama, T. Hirayama, M. Goto, and T. Hirose, "The use of psychrometric charts for the optimisation of a thermal swing desiccant wheel," vol. 21, pp. 1657-1674, 2001. 